\title{
AGENCY COSTS, FAMILY TIES AND FIRM EFFICIENCY
}

\author{
Herrero, Ines \\ Department of Business Management. University Pablo de Olavide. \\ Ctra. de Utrera, Km. 1.- 41011- Seville (Spain). \\ inesherrero@upo.es
}

\begin{abstract}
In this work, we analyze agency costs and their effect on efficiency in the context of small family firms. In particular, we examine the effect that factors such as self-management, having related managers or family employees exert on firm efficiency. We offer some reasoning that may help to clarify agency problems for small firms. We use stochastic frontiers to measure and explain efficiency. Our focus is on small firms in the fishing sector, which are very important entities for the development of certain local communities.
\end{abstract}

Key words: business management, fisheries, agency theory, efficiency, stochastic frontiers, family firms, family contracting, agency costs.

Acknowledgements: This work has been financed by the Ministry of Education and Science of Spain through the Project ECO2009-13378. We are grateful to the Dirección General de Pesca for providing part of the data. The author is very grateful to Steven Michael, the editor that handled the paper and to three anonymous referees for their very useful comments which substantially improved the original manuscript. The author also thanks Ramón Valle and Bárbara Larrañeta for valuable comments on the first drafts of this paper. 


\section{INTRODUCTION}

The study of family firms has become increasingly popular in recent decades (Zahra and Sharma, 2004). From the literature (Schulze et al., 2001), it seems obvious that agency problems exist in family businesses. However, it remains unclear whether they are less prevalent in family businesses than in non-family businesses (Dyer, 2006). Certain studies (Jensen and Meckling, 1976, Anderson and Reeb, 2003, Beehr et al., 1997, McConaughy et al., 2001, Gomez-Mejia et al., 2001, and Daily and Dollinger, 1992, among others) have suggested that family businesses outperform non-family businesses in terms of several dimensions, such as return on assets, return on equity, expectations and advantages, margins, growth, and debt. However, some authors maintain that family firms are poorer performers than are non-family firms-for example, researchers cite the notion that the managers who run family firms are chosen not for their outstanding competence but mainly because of family ties (Schulze et al., 2001). Additionally, some authors suggest that family conflicts often negatively impact labor relationships (Perrow, 1986, Cucculelli and Micucci, 2008). Other authors are ambivalent, failing to find clear evidence that family firms perform either better or worse than non-family firms. What seems clear is that many of the traditional assumptions and governance mechanisms operate differently when firms are privately owned and family managed (Schulze et al., 2001).

However, as some authors have noted (Dyer, 2006), many of the hypotheses and conclusions about family firms that can be found in the literature are mixed and conflicting because such firms are studied in very different contexts. Dyer (2006) analyzed agency costs in family firms by classifying them into four different groups depending on the extent of family assets and family liabilities. We think that small family firms are very peculiar, and consequently it may be interesting to analyze small family firms separately. Accordingly, we focus our analysis on different hypotheses of relevance to small family firms. We try to answer the following key research questions on how the family effect impacts agency costs in small firms. Our first research question is: Are agency costs between owners and related managers of family firms lower than those that exist between owners and non-related managers at non-family firms? This research question examines whether firms with family managers are more efficient than firms with non-family managers (within firms where ownership and management are separated). The second research question analyzes the agency costs of family firms versus non-family firms; we 
analyze this hypothesis by examining the agency problems when there are familial ties between the owner and the non-managerial employees.

A key motivation underlying our analysis is the fact that different authors have expressed conflicting views regarding agency costs in family firms and their performance as compared to that of non-family firms (Dyer, 2006). While Schulze et al. (2003) suggest that the traditional assumptions of agency theory do not hold true for family firms, this idea has not been extensively studied in the literature to date. Although family firms have attracted substantial attention (Zahra and Sharma, 2004), the case of small family firms has been minimally studied (Gomez-Mejia et al., 2001). Our study offers a step in the direction suggested by Gomez-Mejía et al. (2001), analyzing aspects such as agency relationships owner-employees (i.e., the agency problem that may arise between owners and non-managerial employees) that are not addressed in their paper. Our work offers evidence that the arguments against family firms' performing poorly are flawed when the firms are relatively small. There seems to be a gap in the literature in this regard because most studies focus on bigger firms. We argue that a deeper analysis of these issues may help to create a better understanding of the efficiency of small firms.

Although most family firms are very small and simple as well as exhibit a very basic structure, the literature has preferred to focus on larger companies (Gomez-Mejía et al., 2001). One reason for this might be that data regarding this type of firm are difficult to find (Wortman, 1994) and seldom exist in databases that are commonly used by researchers, mainly because smaller firms are privately held and have no legal obligation to disclose financial information (Schulze et al., 2003). Previous studies of family firms have focused on medium-sized companies (as in Schulze et al., 2003) or on family firms quoted on the Spanish stock market (Galve and Salas, 1996), or, most commonly, on firms included in the FORTUNE 500 or other United States databases, which generally only list bigger and more complex companies (as noted by Gomez-Mejía et al., 2001). The present study, following Gomez-Mejía et al. (2001), tries to analyze principal-agent relationships outside the traditional governance framework, conflicting interests among different shareholders or other management issues that may be associated with larger firms. Our study offers a different and unique setting with significant promise for addressing these questions. In our work, we control for industry (by focusing on just one sector), the country effect, size (both 
the family and the non-family firms in our sample are relatively homogeneous), and regulations (all are subject to the same legal issues). This is true for many firms in the fishing industry. Many fleets are composed of micro-size or small enterprises, many of which are family-owned and managed. As a result, their structure is very simple, consisting of the owner, the skipper (manager) and the fishermen. The fact that the firms in our sample are very simple in structure is very relevant to our study because it helps us to analyze agency problems without the interaction of other complex organizational variables. As previously mentioned, our application is quite novel because small enterprises have rarely been analyzed in the literature (Wortman, 1994, Schulze et al., 2003), and the published results to date remain inconclusive (Ibrahim, Angelidis and Parsa, 2008). The research questions that we try to answer are important for the field of management studies. Not only will we try to clarify the conflicting results in the literature regarding family firm studies, but our answers will also try to fill the gap in the literature regarding small (and therefore low-structured) family firms in particular (Wortman, 1994, Schulze et al., 2003). Such firms represent a very important contribution to the economy, as stated by Gramlich (1999). We must take into account that big family firms are very different from small family firms in many respects; in the latter, the sense of family extends across the entire firm, and all of the family members may feel as though they are part of the family business.

We have followed Beehr et al. (1997) and have considered a firm to be a family firm if the manager and/or some of the employees have familial ties to the owner. Note that small family firms often have only a single owner; other shareholders are rare.

Some of the studies in the management literature that try to link different aspects of organizations to performance metrics may fail to achieve their objective because they use inappropriate performance measures (Richard et al., 2009). The methodology we have used to measure efficiency also constitutes a relevant contribution to the business management literature. We use a stochastic frontier analysis protocol, which is a formal technique for measuring efficiency. This is a useful technique that may be helpful in management studies and that may ultimately assist researchers in arriving at a better and more comprehensive definition of efficiency. 
Our paper is comprised of eight sections. In the next section, we present the theory underlying our study and we outline our key hypotheses which is followed by a description of the industry examined. Then, we present our chosen methodology and variables used. Finally we present our results, followed by a discussion, main conclusions and limitations of our study.

\section{THEORETICAL BACKGROUND}

We will start our hypothesis development by trying to answer the first research question. In particular, we will examine whether firms with family managers are more efficient than firms with non-family managers. Toward this end, we will analyze the different solutions that agency theory proposes and suggest reasons why in some cases family ties can act as a substitute for ownership in small family firms.

The traditional agency relationship (Fama and Jensen, 1983a, 1983b) is defined as a situation wherein the agent acts on behalf of another (the principal). Many agency problems arise when the goals of the principal and agent are different and conflicting (this is known as the principalagent problem or the agency dilemma) and when it is difficult or expensive for the principal to verify what the agent is actually doing. According to this theory, the agents should seek to maximize their utility rather than the utility of their firms or the firms' owners. If the principal is not the manager of his (her) own firm, then it may be difficult and costly for the principal to exert control over the agents.

Originally, agency theory focused on the relationship between managers and shareholders (Jensen and Meckling, 1976), but subsequent work has generalized this theory to a wider set of relationships. On the one hand, agency costs may appear when the interests of the owner (principal) and the manager (agent) are not aligned. On the other hand, agency costs may also be involved when the interests of the owner (or the interests of the managers if they act as principals) are not aligned with the interests of the non-managerial employees. Our first hypothesis refers to the reduction of agency costs when the manager is related to the family. Analogously, the second hypothesis refers to the agency costs in family firms - that is, when the 
employees are related to the owner. Although some studies focus on agency problems between owner and manager in family firms (Gomez-Mejia et al., 2001), fewer studies treat agency problems between managers and family employees. Our study will assist in filling this gap because we will explore both types of relationship.

Many studies in the literature maintain that agency problems exist in family businesses (Schulze et al., 2003). However, it is not clear whether the problems are less prevalent in family businesses than in non-family businesses (Dyer, 2006). There is a group of authors who are ambivalent, unable to identify clear evidence that family firms perform better or worse than nonfamily firms. Dyer (2006) analyzes these mixed results and concludes that most of the research fails to describe the "family effect" because authors ignore the industry effect, firm governance, and the characteristics of the firm or the effect of family on management. We argue that when firms are small, the reasons that suggest that family firms are better performers are more valid than those that maintain that family firms perform more poorly. Conversely, the reasons argued to maintain that family firms may exhibit lower performance are more appropriate when one is discussing relatively larger family firms or companies of a more hierarchical design.

For those authors who maintain that family businesses are better performers than non-family businesses in several respects (Jensen and Meckling, 1976, Anderson and Reeb, 2003, Beehr et al., 1997, McConaughy et al., 2001, Gomez-Mejia et al., 2001, and Daily and Dollinger, 1992, among others), several potential explanations exist, including the alignment of principal-agent goals as well as the shared values and high degree of trust among family members. We think that this assertion works well for small family firms that are family-managed because the feeling of being on the same boat may well be shared between owner and manager. When making reference to this relationship between the owner and the manager, some authors (Johns, 1983, Holmes, 1991, Daily and Dollinger, 1992, Anderson and Reeb, 2003) maintain that familymanaged firms outperform non-family-managed firms because they consider the former to be high-trust organizations and assume that the family bonds and the alignment of the manager with the owner due to family ties make them more efficient. 
However, other authors have claimed (Levingson, 1971, Perrow, 1986) that, in a family firm, managers are not chosen in a competitive context, and they secure their position not because of their abilities but because of family ties. According to these authors, this inefficient way of selecting managers leads to weak decisions being made regarding who should be promoted in the firm. These authors argue that the best way for family firms to increase performance is to replace family members with professional managers. Analogously, a reason advanced by other authors (Schulze et al., 2001, Cucculelli and Micucci, 2008) is that family managers have unfair advantages because of family ties and often are not the best candidates for the position; as a result, these authors maintain, family firms exhibit weaker performance. This is known as adverse selection. They argue that managers may lack the education and professionalism needed for their role. In effect, education is assumed to increase efficiency. However, in some activities not related to knowledge intensive firms, like high-tech firms, — and particularly in the case of managing simple small family firms not needed of high knowledge-experience is often considered an alternative to education in the development of skills, competences and abilities (Arrow 1962). Cumulative firm experience and the learning that occurs through this experience may become a source of competitive advantage (Dierickx and Cool, 1989).

Therefore, we suggest that, in small firms (with the exception of those in sectors that are knowledge-intensive), the qualifications needed to manage the firm do not need to be very extensive. In this context, experience and family tradition in the business might constitute a better way of learning and a better substitute for strong professionalism. Managers at family firms commonly cite their broader experience together with a family tradition in the business, which is another reason to argue that family firms should exhibit higher efficiency. As a result, if the family manager may be appropriate for the post in small firms, then executive entrenchment should not represent such an important source of agency cost as is true in the case of larger firms. Moreover, even if it may be thought that incompetent offspring may be pushed into positions for which they have no talent the position of the manager in the context of small businesses is neither high prestigious nor lucrative (unlike, the chairmanship of a large multinational corporation), and hence there may be no pressure on fathers to promote their sons into these positions unless the latter actually want to take them. 
Furthermore, not only may family managers be suitable for the post and reduce the ownermanagers agency costs but also their alignment with the owner might lead the manager to assume a certain responsibility not to disappoint their relatives (the owners), who trusts them sufficiently to delegate authority to them. This responsibility would lead the manager (aligned with the principal) to act as a "controller" of the workers (agents)—which, in turn, should make the agency problem owner-employees smaller than it is for firms that are managed by outsiders. As a result, the related manager would then be acting on behalf of the principal and, in a sense, because he or she would be aligned with the owner due to family ties, the manager should be more eager to defend the principal's interests. In a way we can say that family ties between owner and manager can act as a substitute for ownership

\section{Hypothesis 1:}

Among small firms, those with family-related managers will be more efficient than those whose managers and owners do not have family ties.

Therefore, on the basis of this hypothesis, we provide an answer to the first research question (Are the agency costs for owner and related managers of family firms lower than the agency costs for owner and non-related managers in non-family firms?) regarding the reduction of agency problems in firms with familial ties between manager and owner (i.e., in the case of a family manager).

Other authors point to family employees as the reason that family firms are more (or less) efficient than non-family firms. For example, there is a strong argument against family firms being more efficient: it is more difficult for a family to monitor relatives who work at the firm (Schulze et al., 2001). However, in the case of small firms, the control exerted by the manager over family members is very strong because they work very closely with one another. In small firms, personal relationships and labor relations are tighter among individuals. Related employees are more likely to have a strong feeling of "being part of the business" or that "they are in the same boat", which would align their interests with those of the owner. The absence of a hierarchy may encourage family employees to experience the sense of "belonging to the family 
business," making appropriate goals converge, which should act as an incentive for them to work with enthusiasm and help to eliminate shirking. In contrast, in bigger and highly structured firms, related employees may lose the feeling of being part of a family business, and the distance between their goals and those of the firm will widen if this occurs. Furthermore, in larger family firms, if related employees are not employed at the managerial level, they may feel they are simply employees of a business; this feeling that should be much less overwhelming if the firm is very small.

Some authors (Schulze et al., 2001) suggest that intrafamily conflicts or divergent goals affect labor relations. However, we think that in smaller family firms the feeling of "being in the same boat" is very strong, and the effect of these intrafamily conflicts may be more curtailed. Furthermore, elements mentioned by some authors (Daily and Dollinger, 1992, Anderson and Reeb, 2003), such as family bonds, high trust and alignment with the owner due to family ties, are more important if the family firms we consider are small

Therefore, we have assumed that, within the context of small firms, firms with family employees perform better than non-family firms, which leads us to formulate the following hypothesis:

\section{Hypothesis 2:}

Among small firms, those with family-related employees will be more efficient than non-family firms.

With this hypothesis, we address the second research question that analyzes the agency costs of family firms versus non-family firms as it examines the reduction in agency problems when there are familial ties between the owner and the employees.

\section{AN OVERVIEW OF THE INDUSTRY.}

The fishing industry has many peculiarities and is not represented in many management studies. The fishery we have analyzed is a coastal fishery. The boats go fishing every working day; their fishing trips last for just a few hours (regulated by law), and as a result, the crew does not have to 
spent nights on board, as is the case for high-seas fisheries. Most of the people working in these firms live in the coastal villages, which depend heavily on fishing activities. Furthermore, in these closed coastal communities, the concept of family is very strong. This is a very common feeling in small firms. It is likely that we will be able to confirm for this industry that family employees may have the feeling of "being in the same boat" (because they literally are on the same boat). In this fishery, there is no ship owner who owns more than one vessel. On the one hand, this simplifies the analysis and on the other hand avoids the interaction of this issue. In fishing firms, when the owner is not the skipper of his or her own vessel and there are family members on-board, then the skipper is one of the family members. This offers us a good opportunity to analyze the effect of a family manager being chosen for the primary reason that he/she is a family member. The structural simplicity may be another reason why this sector could also represent a good opportunity to analyze agency costs without the interference of other variables, such as governance or other organizational structures. Analogously, the composition system for all the firms under study is the same because the revenue share system is uniform across all vessels in the fishery (this is the system that the vessels have used for many decades). Similarly, organizational behavior or motivation across the firms analyzed is not expected to vary greatly from one vessel to another because, in these coastal communities, societal and organizational cultures coexist and are intertwined. As a result, and given the homogeneous environment that is a function of the fishing firms of a given coastal community, the effect of family issues can be more easily isolated and detected.

The efficiency of the vessels depends, among other factors, upon the effort exerted by their skippers and fishermen. The skipper may be more keen to complete his or her work and may be quicker in accomplishing his (her) tasks or, on the contrary, be more lax and not put all of his (her) effort into getting the job done. Crewmembers can also change the level of efficiency of the vessels by being ready to develop their tasks in an appropriated way. Among many other things, their attitude will determine how quickly the fish are sorted. The non-target species that get caught have to be classified and a decision has to be made with respect to either discarding them (throwing them back to the sea if they are of low value) or retaining the fish if the species is a high-value one. In some fisheries, crewmembers must also pay attention to the lines so that when enough fish have been caught, they can pull out the lines and throw lines with new bait into the 
sea. This requires experience and the inclination to do it as soon as appropriate. For all fishing tasks, fishermen may exhibit shirking behaviors (laziness) or simply expect others to work harder than them.

A good example of shirking behavior could easily arise during a "bad day at sea". The amount of catch can be affected by random effects and by winds, sea currents, etc. Crewmembers may encounter some days when the amount of captures is disappointingly low. On these days, the non-related skipper may go back to port earlier, thinking that it is not worth the effort to keep on fishing given that conditions are bad, and taking into account that almost half of all revenues will go to the owner (and the remaining portion will be shared). On these occasions, the utility of fishing for the non-related skippers would be insufficient to compensate for their effort and time. In contrast, if the owner is the skipper himself, he may think that the effort is worthwhile regardless. Furthermore, given the latter and assuming a family firm vessel, family employees may also believe that it is worth the effort because the family business will profit from the income. Other factors such as the skipper's skill may also influence the efficiency of the vessels, but these issues are assumed to be randomly spread over the different groups considered in our dataset, and can be captured in the "unexplained" category.

In the fishery we are analyzing wages are variable and based on revenues, though the economic incentives are given equally to all the members of the team. We must take into account some facts that may diminish the effects of economic incentives. First, the crewmembers' share is composed of only half of the revenues minus variable costs, whereas the rest is the ship owner's share. Therefore, an incremental increase in revenues would be halved and then divided by the number of crewmembers, which might not represent a very great increase in the actual wage of each crewmember. This might encourage shirking behavior and could explain why crewmembers exhibit a lack of effort when the ship owner is not the skipper of the vessel. Although the crewmembers' wages depend in a sense on revenues, we must consider that the wage offered to each individual crewmember ${ }^{1}$ is the same independent of the amount of effort exerted by each individual. Therefore, each crewmember may expect others (the rest of the crew) to put forth extra effort but will not do so himself because the extra benefits will be shared equally by the entire crew. Hence, even if wages vary depending on revenues, we must account for the notion 
that wages do not vary individually for each of the crewmembers. The difficulty of distinguishing and controlling for the contributions of each teammate to the work represents one of the inconveniences of teamwork, as reported by Alchian and Demsetz (1972).

\section{METHOD}

\section{Data Analysis.}

We have used stochastic frontiers (SF) which is one of the formal techniques for measuring efficiency. This methodology is an extension of non-linear regression analysis. Regression functions assume that all units are equally efficient and that any difference in their efficiency is purely random. In contrast, SF distinguishes between differences in efficiency from differences due to the stochastic effect. As a result, two random terms appear in SF: the traditional error term and an inefficiency term. The former would account for random variability inherent to any production activity, and the latter can be used to account for persistent deviations from the mean of a certain unit over time, which may be considered the inefficiency associated with that unit. We felt that SF was the most appropriate method to use for our empirical work for several reasons. First, it takes random variation into account, unlike with other formal efficiency techniques and, in our study, the amount of captures fished normally vary from one day to the next. Furthermore, the fishery we are studying is a single species fishery; that is, the fleet has only one main target species (which is caught using a very specific device), and the catches of this species represent the vast majority of all income. One of the key disadvantages of the stochastic frontiers approach is that it can only deal with single-output processes, but this does not represent a disadvantage in this case because the output is expressed in terms of the captures of just one species. Alternatively, we could have used other business methodologies to measure efficiency, such as return on investment (ROI) or return on assets (ROA), but they would have been focused on two variables at most, whereas stochastic frontiers can take into account multiple inputs. Furthermore, in many industries, it can be difficult to assess the economic value of the investments or the effort exerted by the industry, which are variables that can easily be incorporated into a stochastic production frontier without their economic value being properly assessed. In our case, for example, we could take into account the effect of the volume of the 
vessels or the effect of their engine power or number of crewmembers on the efficiency rate without formally calculating the economic value of that factor.

A stochastic frontier can be expressed as follows (Coelli et al., 1998): $Y_{j, t}=F\left(X_{j, i, t}\right)-u_{j, t}+v_{j, t}$ (1), where $Y_{j, t}$ and $X_{j, i, t}$ represent the standardized output of unit $\mathrm{j}$ in time period $\mathrm{t}$ and the $\mathrm{i}$-th input used by unit $\mathrm{j}$ in time period $\mathrm{t}$, respectively. The error term is divided into two parts: stochastic error $\left(\mathrm{v}_{\mathrm{j}, \mathrm{t}}\right)$, which is assumed to be independently and identically distributed (iid) with $\mathrm{N}\left(0, \sigma_{\mathrm{v}}{ }^{2}\right)$ and technical inefficiency $\left(\mathrm{u}_{\mathrm{j}, \mathrm{t}}\right)$, which is assumed to be a non-negative iid random variable. The inefficiency term ranges between 0 (fully inefficient) and 1 (fully efficient).

In our application, we used a translog function ${ }^{2}$. This type of function does not require any assumptions regarding elasticities of production, elasticities of substitution between inputs, or returns to scale. To separate out the stochastic and inefficiency effects in the model, a distributional assumption has to be made regarding $U_{i t}$. We have gone further by using what is termed the technical efficiency effect model (Battese and Coelli, 1995) to estimate the effects of several explanatory variables on the inefficiency rate ${ }^{3}$. The inefficiency effects were defined as a function of the firm-specific factors and were incorporated directly into the maximum likelihood estimation. Therefore the estimation is carried out in a one-step procedure to avoid endogeneity problems by estimating the parameters of the stochastic frontier and the inefficiency model simultaneously. The inefficiency term is assumed to follow the distribution $U_{i t} \sim N\left(m_{i t}, \sigma_{u}{ }^{2}\right)$, so that mean inefficiency is a function of firm-specific factors such that $m_{i, t}=\mathbf{z}_{\mathbf{i}, \mathrm{t}} \delta+W_{i, t}$ where $\mathrm{z}_{\mathrm{i}, \mathrm{t}}$ is the vector of firm-specific variables (which may influence the firm's efficiency) and $\mathrm{W}_{\mathrm{i}, \mathrm{t}}$ is an iid random error term. The use of this model allowed us to test our hypotheses. In this model the technical efficiency rate is given by: $\mathrm{TE}_{\mathrm{i}}=\exp \left(-\mathbf{z}_{\mathbf{i}, \mathrm{t}} \delta-W_{i, t}\right)$.

\section{Data}

We focused on firms that operate in the Gibraltar Strait, fishing for a species known as sea bream. The fleet is composed of small firms (vessels), many of which are family-owned. Nearly $64 \%$ of the vessels have family members on board. This is not a very large-scale fishery, but it is 
very profitable; the vessels operate all year round. The target species is sea bream (paellas bogaraveo), which is a high-value species (the most valuable among all the finfish). The firms in this fleet are characterized by being simple and basic in their structure and organization. They work on a daily basis so that every day they go out to sea to fish and return later that same day. The number of fishing hours per day is limited by applicable regulations so that all of the vessels come back to port at roughly the same time. The fish are then sold at auction, and the daily costs (petrol, food for the crew, bait, etc.) are subsequently subtracted from the revenues. The remainder is then shared between the owner and the crew. The owner takes half of the revenues, whereas the other half is shared among the skipper (who takes a larger part) and crew-members (should the owner be on board, he or she will take another share from this part). This fishery features reasonable good labor conditions because fishermen can go back home every day. This is very different from the situation in high-seas fisheries in which fishermen may spend more than a month on board and far from their homes.

Insert Table 1 about here

Although some studies focus on agency problems between owner and manager in family firms (Gomez-Mejia et al., 2001), fewer researchers have examined the agency problems that may appear between owner and employees in family firms. We have also analyzed this latter type of relationship. In particular, we examine the relation between the owner (principal) and the skipper (agent) as well as the connection between the owner (principal) and the rest of the crew (acting as agents).

Some ship owners are the skippers of their own vessels, whereas others do not go on board because they are too old, because they simply act as firm managers or because they have more than one vessel. If this is the case, the ship owner delegates the management of the firm to an agent (one of the crew) who is designated the skipper. In our study, Hypothesis 2 implies that vessels that have family members on board should be more efficient than those that do not. In contrast, Hypothesis 1 implies that vessels whose skipper is related to the ship owner are more efficient than those whose skipper is not related to the owner.

\section{Sample}


We combined three different datasets. The first dataset consists of certain social and economic information that we obtained from direct interviews with ship owners. These data included variables such as the age of the skipper, whether the skipper was also the ship owner, the number of family members on board, whether the vessel alternates between sea bream fishing and tuna catches, the skipper's experience (number of years) harvesting sea bream, the number of generations working in the fishery sector and whether some of his (her) descendents also planned to work in fishing. Our second dataset covered the daily landings by boat over a period of nine years (1998-2006); this included the number of catches per vessel each day. These were aggregated by year. The total number of observations in the sample was 728 . Finally, we used data from the census, from which we recorded the technical characteristics of the vessels. We cross-correlated the three data sets and removed any observations with data missing for any of the variables; the result was a sample of 91 fishing firms (vessels) operating over 9 time periods. The unit of analysis was each fishing firm in each time period. Therefore, our dataset included practically the entire fleet, which equals approximately 100 vessels at the time of this writing (note that this number varies slightly from one year to another).

\section{Dependent variable (Stochastic Frontier Model).}

For our efficiency analysis, we consider the total catch for each vessel in each time period as the output, $y_{i}$. There are several examples in the literature where either the catch or its value is considered the output of a production function (see Herrero and Pascoe, 2003, for further discussion). In the case of multi-species fisheries with different price points, it is preferable to use the net value of the catch. However, in our case, because we are accounting for just one species, we preferred to measure the catch directly and thereby avoid interference related to price fluctuations.

\section{Independent variables (Stochastic Frontier Model).}

We considered two main inputs in our efficiency analysis: a physical measure of boat capacity (measured in Gross Registered Tons, GRT, for a metric of total capital invested) and the number of trips per month (fishing effort). Its mean and standard deviation values can be found in Table 1. Other inputs would have been available, such as engine power and the number of crewmembers (accounting for human resources). However, to avoid problems of 
multicollinearity due to the simultaneous inclusion of these variables, we decided to include simply the capacity of the vessel because it was a better explanatory variable for inefficiency. Furthermore, nor the official (declared) power of a vessel nor the number of crew members always match its real power.

\section{Dependent variable (Inefficiency Effects Model).}

For our inefficiency effects analysis, we consider the inefficiency rate resulting from the stochastic frontier analysis of each vessel in each time period as the dependent variable. This is bounded between 0 and 1 . Note that both models are estimated in one step to get better estimates.

\section{Independent variables (Inefficiency Effect Model).}

To explain the inefficiency rates, we used several personal, social and organizational variables. The two key variables were whether the manager was family-related to the owner and whether there were family members on board (apart from the manager). Note that the number of crew members was indirectly a variable under control as it was highly correlated with the volume of the vessel. Therefore, as this variable is under control, the number of family employees is a variable that accounts for more related people and not for more people.

\section{Control variables (Inefficiency Effect Model).}

We assume that the traditional assessment of agency theory that the separation of ownership management leads to lower performance levels holds true for family firms (as suggested by some authors, such as Schulze et al., 2003). Therefore, we included a variable indicating whether the skipper and ship owner were the same person.

As previously mentioned, education is assumed to increase efficiency levels. However, in reference to small firms, certain authors (Arrow 1962) have suggested that experience might be a superior alternative to education. Similarly, in fisheries, one may expect that a more experienced skipper or a fishery with a stronger family tradition would achieve better results than others. Kirkley, Squires and Strand (1998) have concluded in previous studies that years of education and years of experience in fishery were positively related to the efficiency of the vessels. Using a deeper analysis, Pascoe et al. (2002) found that experience in fishery exerts a positive influence 
on the efficiency of the vessels. Furthermore, we assume that a long family tradition in fishing should provide fishermen with a better knowledge background, which should result in increased efficiency. The literature confirms that a family tradition in fishing, measured in terms of the number of generations, implies higher levels of efficiency (Tingley et al., 2005). Accordingly, the number of years in the fishing industry and the number of generations were included as variables in our model.

We also assumed that less efficient vessels would be keener to seek out alternative species in search of higher revenues. Alternatively, we could reason this the other way round: we assumed that alternating other fisheries (tuna fishing in this case) would imply a less specificity, experience or knowledge of the sea bream fishery. Therefore whether the vessel alternated between sea bream fishing and tuna fishing was also included as a control variable.

\section{RESULTS}

The results of our analysis suggest that these firms have relative efficiency levels that are quite high $^{4}$, with an average efficiency rate of 0.83 and a standard deviation of 0.16 . The average efficiency rate fluctuated during the period under analysis. However, we must take into account that, over time, the efficiency scores may interfere with the effects of technical change, variations in fishing stocks or weather phenomena (see Pascoe and Herrero, 2004). Nevertheless, these effects do not interfere with the estimation of individual efficiency rates because all vessels operate under the same circumstances in each time period.

Several tests were carried out on the functional form of the model. We used the likelihood ratio test to determine whether the Cobb-Douglas functional form is more appropriate (i.e., all crossproduct coefficients equal zero). However, the Cobb-Douglas production frontier was rejected based on a likelihood ratio test. Similarly, using the likelihood ratio test for one-sided error, we found that we had to reject the null hypothesis of no inefficiency effects. Note that this has a mixed chi-square distribution and that the critical value can be identified in the tables released by Kodde and Palm (1986). Therefore, we conclude that there seems to be a certain degree of inefficiency among the vessels in the fleet. 
We could observe that the coefficient associated with each of the key inputs was significant and had the correct sign. The coefficient ${ }^{5}$ associated with the volume of the vessels (represented by GRT) was highly significant for the fleet. We also observe that the coefficient associated with the second order coefficient of the number of trips is positive. Our results also supported the classical hypothesis of agency theory, which assumes that owner management is related to higher efficiency because it reduces agency costs. We note that if the ship owner and skipper are the same person, then the efficiency level is higher (positive coefficient significant at the 5\% level, with a p-value equal to 0.04 ) giving support to the classical agency assumption that separation of ownership and management give rise to agency costs.

Regarding the efficiency effects model, among those firms that are not own-managed the fact of having a family related manager exerts a positive influence (a positive sign; $p$-value $=0.00$ ) on the performance of the firm (see Table 2) supporting hypothesis 1.

Insert Table 2 about here

Analogously, the larger is the number of family members on board (regardless of the management system), the greater is the efficiency of the vessels (in agreement with hypothesis 2) as suggested by the sign of the coefficient ( $p$-value $=0.00$ ) of the variable "number of family employees" (Table 2).

As expected, the variables related to experience affect positively to the vessel's efficiency.

\section{DISCUSSION}

Although conclusions regarding the performance of family firms are not clear, and conflicting studies can be found in the literature, this paper does at least offer some new and clear-cut reasoning as well as clarifies the case of small family firms. Our work fills the gap that exists in the literature regarding the effect of agency costs on small family firms. 
As some authors have noted, agency costs depend on a firm's context and sector (Gomez-Mejia et al., 2001, Dyer, 2006). In this paper, we have focused on small family fishing firms. Certain authors (Galve and Salas, 1996) argue that family firms tend to be the least capital intensive, implying that they operate with a sub-optimal rate of return. We focused our analysis on family and non-family firms of similar size so that the effect of size would not affect the firms' efficiency. This allowed us to isolate the effect of agency costs.

According to agency theory, the skippers (agents) look to maximize their utility and not the utility of their firms (the vessels) or their owners (ship owners). In the case of fishing firms, if the principal is not the manager (skipper) of his (her) own vessel, then it may be very difficult for the principal (ship owner) to exert control over the agents. Therefore, in vessels where the skipper is also the ship owner, this divergence of interests will disappear. However, on those vessels for which the skipper is not the ship owner, there may be a divergence of interests that will create an agency problem, leading the vessel in question to be less efficient (or at least to appear less efficient if they can miss part of their catch). This is what Arrow (1985) defines as the moral risk problem. We observed an efficiency boost if the skipper and the ship owner are the same person.

The key suggestion that agency theory makes for aligning the interests of principals and agents is the offer of economic incentives-i.e., it is believed that firms should establish variable wages based on revenues. This is actually the case in the fleet we are analyzing. However, we must take into account two facts that may diminish the effect of economic incentives. On the one hand owner-captains make the most of the revenues and will work the hardest, family-member captains have the second largest stake and will work the second-hardest, whereas the crewmembers' share is the lowest, so that an increase in the effort might not represent a very great increase in the actual wage of each crewmember. Furthermore, even if wages vary depending on revenues, we must account for the notion that wages do not vary individually for each of the crewmembers. The difficulty of distinguishing and controlling for the contributions of each teammate to the work have traditionally considered to represent one of the inconveniences of teamwork (Alchian and Demsetz, 1972). 
In any case, if we assume that we are dealing with team work (which reduces the effect of economic incentives), family employees and non-family employees have the same economic incentives but according to our results the former ones perform better. Similarly family managers and non-family managers have the same economic incentives but the former ones again seem to perform better than the latter.

Another question that may arise is whether the vessels whose managers are not family members are really less efficient or simply declare lower catch volumes. This may also be strongly linked to the agency problem, where the agent would be acting (illegally) in his (her) own interests and not in the principal's interests. According to this reasoning, illegal landings or non-reported catches could represent a sort of opportunistic behavior whereby the agent would be acting in his (her) own interest and not for the benefit of the principal. In this case, the firms would appear to exhibit poor efficiency according to official statistics. In practice, this opportunistic behavior and the shirking behavior mentioned previously would lead us to draw the same conclusion, confirming the existence of an agency problem between principal and agent. If this were the case, according to the results, family managers would not present this type of behavior or at least it would be less frequent.

Another incentive that may reduce agency costs is promotion. However, this can hardly be true for small firms. In our case, the only kind of promotion that one can offer a fisherman is that of a skipper, but this position is normally reserved for the owner or one if his (her) relatives. When there is no relative who can hold the position, another crewmember is selected, and there is rarely more than one individual with the qualifications necessary for such work. To establish a control system for monitoring the agents' performance as a method of reducing agency costs may also prove difficult in small firms. This is true for fishing activity when the ship owner is not on board. We face the problem of asymmetric information, which is one of the main causes of agency problems. In this sector, the agency problem may be aggravated by the fact that the principal when not on board exerts very limited control over the agents (because the daily catch may vary from one day to another due to random factors like weather conditions, sea currents or simple luck). This variability makes it very difficult for the principal to ascertain the cause of a 
decrease in revenues and to determine whether this is due to unacceptable crew effort levels or to the influence of some other random variable.

Even if the above reasoning confirm the existence of an agency problem between principal and agent, we argue that family ties can diminish these problems. In the case of family managers, the family ties can act as a substitute for ownership, whereas family employees may diminish the agency costs between manager and employees. Effectively, results suggest that, if the ship owner and skipper have family ties, then efficiency is higher. This supports the hypothesis we set assuming that agency problems between owner and manager are reduced in the case of family managers. Analogously, the number of family members on board is positively related to the efficiency levels of the vessels, which is in agreement with hypothesis 2 . This is consistent with results from other examples in the literature (Jensen and Meckling, 1976, Anderson and Reeb, 2003, Beehr et al., 1997, McConaughy et al., 2001, Gomez-Mejia et al., 2001, and Daily and Dollinger, 1992, among others).

Similarly to previous analyses (Kirkley et al., 1998, Tingley et al., 2005 Pascoe et al., 2002), it seems that the variables related to experience - in our case, a family tradition in fishing (in terms of the number of generations) and the experience of the skipper with sea bream fishing in particular (represented by the number of years spent fishing) — is positively related to the efficiency rate of the vessel.

We conclude that, small firms with family employees performed better than non-family firms, which is consistent with some other examples that have appeared in the literature (Anderson and Reeb, 2003, Beehr et al., 1997, McConaughy et al., 2001, Gomez-Mejia et al., 2001, and Daily and Dollinger, 1992, among others). This implies that the agency problem is reduced in the case of family employees (supporting hypothesis 2). We assumed that one key reason may be that, in the context of small family firms, family members have a stronger sense of "belonging to the family business," which aligns the interests of the owner and his (her) subordinates, and because these various actors work in close contact, facilitates the control that the principal exerts over the agents. This idea is reinforced by our results in the case of a separation between ownership and management. In this case, the agency costs are reduced when the manager has family ties to the 
owner (supporting Hypothesis 1) because the results suggest that, among firms where the ownership and management are separate, those with managers in the family exhibit better efficiency than those with outside managers. We assume that the related manager not only has interests that are closer to those of the owner (reducing the agency problem between them) but also that the agency problem between owner and employees diminishes because the related manager could be acting as a principal, controlling the agents and watching over the owner's interests.

Both types of agency costs (owner-manager and manager-subordinates) are highest for nonfamily firms in which ownership and management are separate, implying that non-family management and non-family subordinates should lead to the lowest efficiency levels for small firms.

From this discussion, we conclude that even if nepotism is a bad practice and is believed to have negative societal effects in politics and public positions, it may have a positive influence on firm efficiency in the context of small private businesses and particularly in small family firms. A family member with experience, immersed in the family business tradition and in the firm's organizational culture, may achieve better results than an external manager with a less relevant educational background.

As suggested by others (Dyer, 2006), this study is set in a very specific context: small family firms. We have argued that this context should be differentiated from that of bigger family firms because the latter, in a sense, lose their "family peculiarities". Unfortunately, the present work has only considered a very particular sector: the fishing sector. It would be helpful to extend the study to a wider variety of firms in different industrial sectors and to firms with a wider variety of organizational structures so that more general conclusions may be drawn based upon the results. This is left for future research.

In summary, we feel that our paper aids in the understanding of agency relationships within small firms and how they affect efficiency, which may help us to discover the reasons for their success or failure. 


\section{REFERENCES}

Aigner D., Lovell, C.A.K., Schmidt, P., 1977. Formulation and estimation of stochastic frontier production function models. Journal of Econometrics, 6, pp. 21-37.

Alchian, A.A. \& Demsetz, H., 1972: Production, Information Cost and Economic Organization, American Economic Review, 62, pp. 777-795.

Anderson, R.C. \& Reeb, D., M., 2003. Founding-family ownership and firm performance: evidence fron the S\&P 500, Journal of Finance, 58, pp. 1301-1328.

Arrow, K.J., 1985. The Economics of Agency in Principals and Agents: The Structure of American Business, Boston, Harvard Deusto Business School Press.

Barney, J.B. \& Hesterly, W., 1996. Organizational Economics: Understanding the Relationship between Organizations and Economic Analysis, en Clegg, S.R; Hardy, C. y Nord, W.R. (eds.), Handbook of Organization Studies, Sage, Londres, pp.115-147.

Barney, J.B \& Ouchi, W.G., 1986. Organizational Economics, Jossey-Bass. San Francisco.

Battese, G.E., Coelli, T. J., 1988. Prediction of firm level technical inefficiencies with a generalised frontier production function and panel data. Journal of Econometrics, 38, pp. 387-399.

Battese, G.E. \& Coelli, T.J., 1995. A model for technical inefficiency effects in a stochastic frontier production function for panel data. Empirical Economics, 20 (2), pp. 325-332.

Beehr, T., Drexler, J.A. \& Faulkner, S., 1997. Working in small family business: empirical comparisons to non-family business. Journal of Organizational Behaviour, vol. 18 (3), pp. 297-312.

Certo, S.T., Holcomb, T.R., Holmes, R.M. (forthcoming). IPO Research in Management and Entrepreneurship: Moving the Agenda Forward. Journal of Management, forthcoming.

Cucculelli M. \& Micucci, G., 2008. Family succession and firm performance: Evidence from Italian family firms. Journal of Corporate Finance, vol. 14 (1), pp. 17-31.

Daily, C.M. \& Dollinger, M.J., 1992. An empirical examination of ownership structure in family and professional managed firm. Family Business Review, 5 (2), pp. 117-136. 
Dierickx, I. \& Cool, K., 1989. Asset stock accumulation and sustainability of competitive advantage. Management Science, 35(12), pp. 1504-1511.

Dyer, W.G., 2006. Examining the "Family Effect" on firm performance. Family Business Review, 19 (4), pp. 253-273.

Eisenhardt, K. M., 1985. Control: Organizational and economic approaches. Management Science, 31(2), pp.134.

Eisenhardt, M, K., 1989. Agency theory: An assessment and review. Academy of Management Review, 14(1), pp. 57-74.

Fama, E.F. \& Jensen, M.C., 1983a: Agency problems and residual claims; Journal of Law and Economics, 26, pp. 301-326.

Fama, E.F. \& Jensen, M.C., 1983b- Separation of Ownership and Control; Journal of Law and Economics, 26, pp. 325-344.

Fizel, J. L. D’Itri, M.P., 1999. Firing and Hiring of Managers: Does Efficiency Matter? Journal of Management, 25(4), pp.567-585.

Freeman, E., 1984. Strategy Management: a stakeholder approach. Boston. Pitman Press.

Galve-Gorriz, C. \& Salas-Fumás, V., 1996. Ownership Structure and Firm Performance: Some Empirical Evidence from Spain. Managerial and Decision Economics, 17, pp. 575-586.

Ghobadian, A. and O'Reagan, N., 2006. The impact of ownership on Small Firm Behavious and Performance. International Small Business Journal, 24, pp. 555-586.

Gomez-Mejia, L.R., Nuñez-Nickel, M. \& Gutierrez, I.,, 2001. The role of family ties in agency contracts. Academy of Management Journal, 44 (1), pp. 81-95.

Gramlich, E. M., 1999. http://www.federalreserve.gov/boarddocs/speeches/1999/19990915.htm BusinessLINC and Small Business Technical Assistance Conference, Washington, D.C. September 15, 1999.

Herrero, I. \& Pascoe, S., 2003. Volume vs value in the Catch of the Spanish South-Atlantic Trawl Fishery. Journal of Agricultural Economics, 54(2), pp. 325-342.

Herrero, I., 2004. Risk and Strategy of Fishers Alternatively Exploiting Sea Bream and Tuna in the Gibraltar Strait Using an Efficiency Perspective. ICES Journal of Marine Science, 61 (2), pp. 230-236. 
Herrero, I., 2005. Different Approaches to Efficiency Analysis. An application to the Spanish Trawl Fleet Operating in Moroccan Waters. European Journal of Operational Research, vol. 167 (1), pp. 257-271.

Howard, L. W. \& Miller, 1993. J. L. Fair pay for fair play: estimating pay equity in professional baseball with data envelopment analysis. Academy of Management Journal, 36 (4), pp. 882-894.

Huang \& Liu, 1994. Estimation of a non-neutral stochastic frontier production function. Journal of Productivity Analysis; 5(2), pp.171-180.

Ibrahim N. A., Angelidis J. P. \& Parsa F., 2008) Strategic Management of Family Businesses: Current Findings and Directions for Future Research. International Journal of Management, vol. 25 (1), pp. 95-110.

Illueca, M. \& Lafuente, J.A., 2003. Productivity and scale effect in closely related firms: evidence from the Spanish tile sector. International Small Business Journal, 21, pp. 161180.

Jensen, M.C. \& Meckling, W.H., 1976: Theory of the Firm: Managerial Behaviour, Agency Cost and Owership Structure, Journal of Financial Economics, 3, pp. 305-360.

Jondrow, J., Lovell, C.A.K., Materov ,I.S. and Schmidt, P., 1982. On the estimation of technical inefficiency in the stochastic frontier production function model, Journal of Econometrics, 19, pp. 223-238.

Kirkley, J.E., D. Squires \& I.E. Strand, 1998. Characterizing managerial skill and technical efficiency in a fishery. Journal of Productivity Analysis, 9, pp.145-160.

Kodde D.A. \& F.C. Palm,, 1986. Wald criteria for jointly testing equality and inequality restrictions. Econometrica, 54(5), pp. 1243-1248.

Majumdar, S. K. \& Marcus, A. A., 2001. Rules versus discretion: the productivity consequences of flexible regulation. Academy of Management Journal, 44(1), pp.170-179.

McConaughy, D.,L., Matthews, C.H. \& Fialko, A.S.,, 2001. Journal of Small Business Management, 39 (1), pp. 31-49.

Naldi, L., Nordqvist, M., Sjöberg, K. \& Wiklund, J., 2007). Entreprenurial Orientation, risk taking and performance in family firms. Family Business Review, 20 (1), pp. 33-47. 
Ouchi, W.G., 1980. Markets, bureaucracies and clans. Administrative Science Quarterly, 25, pp. 129-141.

Pascoe, S. \& Coglan, L., 2002. The contribution of unmesurable inputs to fisheries production: an analysis of technical efficiency of fishing vessels in the English Channel. American Journal of Agricultural Economics, 84(3), pp. 585-597.

Pascoe, S. \& Herrero, I., 2004. Estimation of Stock Indexes Using DEA. Fisheries Research, 69(1), pp. 91-105.

Perrow, C., 1986. Complex Organizations. New York. Random House.

Richard, P. J., Devinney, T. M., Yip, G. S., Johnson, G., 2009. Measuring Organizational Performance: Towards Methodological Best Practice. Journal of Management, 35 (3), pp.718-804.

Schulze, W.S., Lubatkin, M. H., Dino, R. N. \& Buchholtz, A., K., 2001. Agency relationships in family firms: theory and evidence. Organization Science, Vol. 12 (2), pp.99-116.

Schulze, W.S., Lubatkin, M. H. \& Dino, R. N., 2003. Exploring the agency consequences of ownership dispersion among the directors of private family firms. Academy of Management Journal, Vol. 46 (2), pp.179-194.

Tingley, D., Pascoe, S. \& Coglan, L., 2005. Factors affecting technical efficiency in fisheries: stochastic production frontier versus data envelopment analysis approaches. Fisheries Research 73, pp. 363-376.

Wiseman, R.M. \& Gomez-Mejia, L.R., 1998. A behavioural agency model of managerial risk taking. Academy of Management Review, 23(1), pp. 133-153.

Wortman, M. S. \& Jr. 1994. Theoretical foundations for family-owned business: A conceptual and research based paradigm. Family Rusiness Review, 7(1), pp.3-27. 


\section{FOOTNOTES}

${ }^{1}$ Apart from extra wages for certain tasks like captaincy.

${ }^{2}$ A stochastic translog production frontier can be expressed as follows (Herrero, 2005):

$\ln Y_{i t}=\beta_{0}+\sum_{k} \beta_{k} \ln X_{i k t}+\frac{1}{2} \sum_{k} \sum_{j} \beta_{k j} \ln X_{i k t} \ln X_{i j t}+V_{i t}-U_{i}$

The term $U_{i}$ represents technical inefficiency. When $U_{i}=0$, the $i$-th firm lies on the stochastic frontier and hence can be considered technically efficient at time $t$. If $U_{i}>0$, production lies below the frontier, and hence the firm is inefficient. The measure of technical efficiency of the firm $i\left(T E_{i}\right)$ when working with logged variables is given by (Coelli et al., 1998):

$T E_{i}=e^{-U_{i}}$

This efficiency measure ranges from 0 (when the firm is fully inefficient) to 1 (when the firm is fully efficient). The error term $V_{i t}$ is assumed to be independently and identically distributed (iid) $\mathrm{N}\left(0, \sigma_{\mathrm{v}}{ }^{2}\right)$.

${ }^{3}$ Note that if we used a regression analysis, we would be measuring the effect of these variables on the output variable whereas when using SF, we are measuring the effect of these variables on the efficiency rate of the units. ${ }^{4}$ Note that efficiency is a relative concept because it depends on the set of observations we are using. Thus, this result only means that there are no major differences in performance between the different vessels. Efficiency rates range between 0 and 1 .

${ }^{5}$ The value of all variables was normalized using its mean value such that the mean logged value of the variables was zero (see Huang and Liu, 1994). This normalization enables the elasticities associated with each of the inputs to be derived directly from the coefficient of its level in the stochastic production frontier. 


\section{TABLES}

TABLE 1.

Means, Standard Deviations, and Correlations for all variables.

Average St. Dev. Years in fishery No.of generations in fishery No. of family employees Having a Fam. Manager

Years in fishery
No. of generations in fishery
No. of family employees
Having a Fam. Manager

$\begin{array}{rrr}19.84 & 9.41 & 1 \\ 1.46 & 0.83 & 0.25 \\ 1.31 & 1.49 & 0.04 \\ 0.36 & 0.48 & 0.03\end{array}$

4

$\begin{array}{rr}1 & \\ 0.09 & 1 \\ 0.08 & 0.29\end{array}$

\section{TABLE 2.}

\section{Coefficients of the inefficiency effects model}

\begin{tabular}{|c|c|c|c|}
\hline Inefficiency effects model (1) & Beta & p-value & \\
\hline Constant & -1.91 & 0.000 & *** \\
\hline Years in the fishery & 0.34 & 0.005 & *** \\
\hline No. of generations dedicated to fishing & 0.00 & 0.015 & * \\
\hline Number of family crew members & 0.13 & 0.000 & *** \\
\hline Family-related manager & 0.09 & 0.036 & * \\
\hline sigma-squared & 0.22 & 0.000 & ** \\
\hline Gamma & 0.84 & 0.000 & *** \\
\hline
\end{tabular}

(1) Note that the sign of the coefficients of the inefficiency effects model have been changed for a better understanding, so that they represent the effect on the efficiency levels rather than the inefficiency levels. 